\title{
ORAL MANIFESTATIONS OF SYPHILIS: A REVIEW
}

\author{
SOARES A.B. ${ }^{1}$; GONZAGA H.F.S. ${ }^{2}$; JORGE M.A. ${ }^{3}$; BARRAVIERA S.R.C.S. ${ }^{4}$ \\ ${ }^{1}$ Faculdade de Odontologia de Piracicaba, Universidade de Campinas (UNICAMP), São Paulo, Brasil; \\ ${ }^{2}$ Programa de Pós-Graduação em Estomatopatologia, Faculdade de Odontologia, UNICAMP, \\ Piracicaba, São Paulo e Faculdade de Medicina de Marília (UNIMAR), Marília, São Paulo, Brasil; \\ ${ }^{3}$ Centro de Ensino Superior de Dracena (CESD), Dracena, São Paulo, Brasil; ${ }^{4}$ Faculdade de Medicina, \\ Universidade Estadual Paulista (UNESP), Botucatu e Centro de Estudos de Venenos e Animais \\ Peçonhentos (CEVAP), Botucatu, São Paulo, Brasil.
}

\begin{abstract}
Syphilis is an infectious disease presenting stages associated with specific oral lesions. Therefore, health professionals should be familiar with the different syphilis oral manifestations at each stage and be prepared to refer any suspected patient for further evaluation. This report describes the most important clinical factors of each stage, emphasizing the oral manifestations.
\end{abstract}

KEY WORDS: Syphilis, oral lesions, Treponema pallidum.

\section{CORRESPONDENCE TO:}

H. F. S. GONZAGA - Rua Clemente Ferreira, 360, Bairro Maria Isabel, Marília, São Paulo, 17515-440.

E-mail: herongonzaga@terra.com.br 


\section{INTRODUCTION}

Syphilis is an infectious disease of utmost importance nowadays, which has made a comeback after the appearance of AIDS.

It may present oral lesions in all stages. A keen knowledge of its various oral manifestations is important for proper diagnosis and adequate treatment.

In this paper, the authors made a literature review on etiology, transmission, classification, clinical manifestation, diagnosis, and treatment.

\section{Etiology and Transmission}

The etiological agent of syphilis is the spirochete Treponema pallidum. Humans are the only known vectors $(15,19)$. Transmission occurs via oral-genital, oral-anal, or other sexual contact, transfusion with contaminated blood, direct contact with contaminated material, and intra-uterine transmission $(4,15,19)$.

Syphilis been known for many centuries as a virulent and potentially fatal disease after its introduction in Europe at the end of the fifteenth century (2). In 1943, with the introduction of penicillin, its incidence has decreased, and it became rare. However, during the past few years, incidence of syphilis has increased, and it has been epidemiologically related to human immunodeficiency virus (HIV) disease. Syphilis is the fourth most commonly reported infectious disease in the United States, only losing out to gonorrhea, varicellae, and AIDS $(5,15,19)$.

Syphilis genital ulcerations represent a risk factor for HIV sexual transmission because they are an entry for viral particles, and in turn, HIV infection may affect the natural course of syphilis and respond to treatment $(13,16,20)$. In HIV patients, syphilis may follow a malignant and protracted course; it is associated with serious neurological complications and frequent relapses after conventional therapy $(6,10,11,16,22)$. 


\section{Classification}

Syphilis can be classified as either congenital or acquired (15). The acquired form can be classified as primary, secondary, latent, and tertiary, depending on the elapsed time after exposure; primary and secondary are defined as present for one year or less after the initial infection; late syphilis is present for more than one year. Congenital syphilis is transmitted to newborns in uteri, and depending on the time of the manifestation is classified as recent or late.

\section{Primary Syphilis}

The initial lesion is called chancre, appearing one to two weeks after exposure to the Treponema; the primary stage occurs at the site of inoculation. However, incubation can last up to 40 days $(15,19)$. The lesion is usually erosive or ulcerated, singular, painless, with base infiltration and hardened high margins, frequently occurring in ano-genital and oral regions. After the appearance of the chancre, regional lymphadenopathy occurs. Spontaneous healing of the chancre occurs within three to six weeks, and scars at the site are not commonly seen $(15,19)$.

The increase in oral sex has had a resultant increase of the incidence of primary syphilis oral manifestations $(1,17)$. In the oral region, lesions may vary in clinical appearance. An indurate ulceration of the tongue dorsum, accompanied by hyperplasic foliate papillae, may be the only clinical signs of the disease. Erythema, edema, and petechial hemorrhage with or without the presence of a chancre may occur in the soft palate. Asymmetry of the uvula or tonsillar pillar may be evident $(3,19)$. Crateriform intra-oral ulcerations with a yellow-colored transudate accompanied by non-tender regional lymphadenopathy should be viewed with suspicion in patients at risk of acquiring sexually-transmitted diseases (3). Differential diagnosis for intraoral syphilis includes herpetic or fungal infections, tuberculosis, histoplasmosis, squamous cell carcinoma, or trauma $(15,19)$.

\section{Secondary Syphilis}

Secondary syphilis is the general systemic component of the disease; therefore, lesions contain highly contagious spirochetes. Their manifestation occur from four to eight weeks after chancre emergence $(15,19)$. 
Initially, the lesion is symmetrical, coppery-red, with round and oval spots of no substance called roseolar rash. Later, it may show papular cutaneous rash with palm and sole involvement, condylomata lata, mucous patches, generalized microlymphadenopathy, and papulosquamous lesions in glans (19). Signs such as renal disease, arthralgy, and arthritis may be related to an immune response to the spirochete $(4,19)$. These lesions disappear even without treatment due to the emergence of antibodies that develop relative immunity.

In contrast with first-stage syphilis, secondary oral lesions are typically painful and multiple and may be accompanied by concomitant cutaneous eruption, fever, migraine, and sore throat (12).

Oral lesions are of two basic types: a macular and papular eruption or the mucous patches, the latter being the most common. $(7,12,14)$. These tend to be oval or serpiginous, slightly raised erosions or shallow ulcers with an erythematous border. There is overlying gray or silver white membranous exudates. On the distal and lateral tongue, lesions tend to be more ulcerated and irregular fissures may appear $(7,12,14,19,23)$. Differential diagnosis of secondary syphilis includes infectious and non-infectious conditions with accentuated eruption (15).

\section{Tertiary Syphilis}

Tertiary syphilis occurs after one year of evolution in patients who have not received treatment in either primary or secondary stages (19). The characteristic destructive lesion of this phase, the gumma, may represent the chronic hypersensitivity reaction to the presence of spirochete (19). Clinical manifestations can appear after a variable latency and more frequently occur in cutaneous, cardiovascular, and nervous forms $(1,13,15,18)$.

Intraorally, the gumma is often seen on the hard palate as a chronic, progressive, granulomatous lesion that may perforate through the palatal bone into the nasal septum. The tongue appears atrophic, fissured, or lobulated, and leukoplakic plaque is usually present dorsally. Follow up every three to six months and biopsy are recommend because literature related possible malignant transformation of the lesion (19). It is important to know that tertiary syphilis is not infectious. 


\section{Congenital Syphilis}

Congenital syphilis is transmitted in the uterus from the infected mother to the fetus after the 16th week of pregnancy because there are Langerhans cells in the placenta that prevents transmission of the spirochete up to the first 16 weeks. With fetal development, there is reduction of these cells, facilitating the passage of spirochetes $(7,9,15,18)$.

Fetal contamination can cause abortion or stillbirth, depending on infection severity and extension. However, when penetration of the treponemas is late and/or in small number, the child can be born with clinical signs of recent congenital syphilis. On the other hand, if fetal infection is little intense, the child can be born seemingly normal, and during development manifests late congenital syphilis $(19,21)$.

Systemic manifestations of congenital syphilis acquired in the second trimester of pregnancy include ectodermic changes, mucocutaneous rash, osteochondritis, periostitis, and rhinitis. Infection can destroy the vomer, resulting in the development of saddle nose $(15,19)$.

Systemic manifestations of late congenital syphilis are recognized by a classic triad of findings referred to as Hutchinson's triad: (1) interstitial keratitis of the cornea, (2) eighth nerve deafness, and (3) dental abnormalities. Dental abnormalities are probably caused by spirochetal infection of the enamel organ, causing screwdriver-shaped incisor (Hutchinson’s incisors) and Mulberry molars $(7,9,15,19)$. Other intra-oral findings may include atrophic glossitis, palatal cleft, and perioral rhagades (fissures) $(15,19)$.

\section{Diagnosis and Treatment}

Diagnosis is commonly made by serologic testing. The most commonly used screening tests are the Rapid Plasma Reagin (RPR) and the Venereal Disease Research Laboratory (VDRL). These are non-specific, non-treponemal tests that use reagin, cardiolipin-lecithin-cholesterol antigens to test for antibodies against $T$. pallidum. The most specific serologic tests for syphilis are the fluorescent treponemal antibody absorption test and the microhemagglutination test. These detect antibodies that are produced against treponemal antigens $(8,15,19)$.

Dark-field microscopic examination to detect spirochetes is essential in evaluating cutaneous lesions, such as the chancre of primary syphilis or the condylomata lata of secondary syphilis. 
However, examination of oral lesion by this method is not recommended, since another treponemal organism is normally present in the oral cavity and can confuse diagnosis $(15,23)$.

Treatment of choice for primary or secondary syphilis is to two-team doses of benzathine penicillin G, 2.4 million units intramuscularly, applied one week apart, and for tertiary syphilis three to four doses. Patients who are allergic to penicillin may be treated with either ceftriaxone or tetracycline $(15,19)$.

\section{CONCLUSION}

Syphilis is a disease with extremely varied clinical manifestations. Practically all organs and systems may be compromised in its clinical stages. It must be highlighted that oral manifestations may be exclusive. Oral evaluation is a must in all patients under this condition.

\section{REFERENCES}

1 AARESTRUP FM., VIEIRA BJ. Oral manifestation of tertiary syphilis: case report. Braz. Dent. J., 1999, 10, 117-21.

2 ANDERS PL., DRINNAN AJ., THINES TJ. Infectious diseases and the dental office. $\boldsymbol{N}$. Y. State Dent. J., 1998, 64, 29-34.

3 BRICKER SL., LANGLAIS RP., MILLER CS. Sexually transmitted disease. In: Oral diagnosis, oral medicine, and treatment planning. 2.ed. Philadelphia: Lea \& Febiger, 1994: 752-79.

4 BRIGHTMAN VJ. Sexually transmitted and bloodborne infections. In:

Burkett's oral medicine: diagnosis and treatment. 9.ed. Philadelphia: JB Lippincott, 1994: 629-53.

5 CENTERS FOR DISEASE CONTROL. Special focus. Surveillance for sexually transmitted disease. MMWR, 1993, 42, supl.3, i-39.

6 ENGELKENS HJH., VAN DER SLUIS JJ., STOLZ E. Syphilis in the AIDS. Int. $\boldsymbol{J}$. Dermatol., 1991, 30, 254-6.

7 FIUMARRA NY., GRANDE DJ., GUINTA JL. Papular secondary syphilis of the tongue. Oral Surg., Oral Med., Oral Pathol., 1978, 45, 540-2. 
8 HOOK EW., MARRA CM. Acquired syphilis in adults. N. Engl. J. Med., 1992, 326, 1060-9.

9 HOUSEGO HONS T., WOOD RE., GROTEPASS F., NORTJE CJ. Repair of palatal defect associated with late congenital syphilis using a tongue flap. $\mathbf{J}$. Oral Maxillofac. Surg., 1988, 46, 70-3.

10 HUTCHINSON CM., HOOK EW. Altered clinical presentation of early syphilis in patients with human immunodeficiency virus infection. Ann. Intern. Med., 1994, 121, 94-9.

11 JONHS DR., TIERNEY M., FELSENTEIN D. Alteration in the natural history of neurosyphilis by concurrent infection with the human immunodeficiency virus. $N$. Engl. J. Med., 1987, 316, 1569-72.

12 JUNKINS-HOPKINS J. Multiple painful oral ulcerations. Arch. Otolaryngology-Head Neck Surg., 1995, 137, 833-8.

13 KEARNS G., POGREL MA., HONDA G. Intraoral tertiary syphilis (Gumma) in a human immunodeficiency virus-positive man: a case report. J. Oral Maxillofac. Surg., 1993, 51, 85-8.

14 MANI NJ. Secondary syphilis initially diagnosed from oral lesions. Oral Surg., 1984, 58, 47-50.

15 MONHIAN N., MURR AH., MANDPE AH., BAEHNER FL. Pathology forum. Quiz case 1. Secondary syphilis. Arch. Otolaryngology-Head Neck Surg., 2001, 127, $217-$ 9.

16 RAMIREZ-AMADOR V., DE LA ROSA GARCIA E., GUEVARA MG., GUTIERREZ ER., REYES-TERAN G. Oral secondary syphilis in a patient with human immunodeficiency virus infection. Oral Surg., Oral Med., Oral Pathol., Oral Radiol. Endod., 1996, 81, 652-4.

17 RAPOSO VM., ZALLEN RD. The resurgence of syphilis: a case report of oral cutaneous secondary syphilis. J. Colo. Dent. Assoc., 1997, 76, 18-9.

18 SCULLY C. Infectious diseases: review of the literature. Word workshop on oral Medicine. Chicago, 1993. 23. 
19 SIEGAL MA. Syphilis and gonorrhea. Infect. Dis. Dent., 1996, 40, 369-83.

20 SIMONSEN JN., CAMERON DW., GAKINYA MN., NDINYA-ACHOLA JO., D'COSTA LJ., KARASIRA P., CHEANG M., RONALD AR., PIOT P., PLUMMER FA Human immunodeficiency virus infection among men with sexually transmitted diseases. N. Engl. J. Med., 1988, 319, 274-8.

21 STOLL BJ. Congenital syphilis. Evaluation and management of neonates born to mothers with reactive serologic tests for syphilis. Pediatr. Infect. Dis. J., 1994, 13, 845-51.

22 TRAMOONT EC. Syphilis in the AIDS era. N. Engl. J. Med, 1987, 316, 1600-19.

23 WONG PNC., DENT BSC. Secondary syphilis with extensive oral manifestations. Aust. Dent. J., 1985, 30, 22-4. 